\title{
Optimisation of medications used in residential aged care facilities: a systematic review and meta-analysis of randomised controlled trials
}

\author{
Hend Almutairi ${ }^{1 *} \mathbb{D}$, Andrew Stafford ${ }^{1}$, Christopher Etherton-Beer ${ }^{2}$ and Leon Flicker ${ }^{3}$
}

\begin{abstract}
Background: Frail older adults living in residential aged care facilities (RACFs) usually experience comorbidities and are frequently prescribed multiple medications. This increases the potential risk of inappropriate prescribing and its negative consequences. Thus, optimising prescribed medications in RACFs is a challenge for healthcare providers.

Objective: Our aim was to systematically review interventions that increase the appropriateness of medications used in RACFs and the outcomes of these interventions.

Methods: Systematic review and meta-analysis of randomised control trials (RCTs) and cluster randomised control trials (CRCTs) were performed by searching specified databases (MEDLINE, PubMed, Google scholar, PsycINFO) for publications from inception to May 2019 based on defined inclusion criteria. Data were extracted, study quality was assessed and statistically analysed using RevMan v5.3. Medication appropriateness, hospital admissions, mortality, falls, quality of life (QoL), Behavioural and Psychological Symptoms of Dementia (BPSD), adverse drug events (ADEs) and cognitive function could be meta-analysed.

Results: A total of 25 RCTs and cRCTs comprising 19,576 participants met the inclusion criteria. The studies tested various interventions including medication review $(n=13)$, staff education $(n=9)$, multi-disciplinary case conferencing $(n=4)$ and computerised clinical decision support systems $(n=2)$. There was an effect of interventions on medication appropriateness (RR 0.71; 95\% confidence interval (CI): 0.60,0.84) (10 studies), and on medication appropriateness scales (standardised mean difference $=-0.67 ; 95 \% \mathrm{Cl}:-0.97,-0.36)$ (2 studies). There were no apparent effects on hospital admission (RR 1.00; 95\% Cl: 0.93, 1.06), mortality (RR 0.98; 95\% Cl: 0.86, 1.11), falls (RR 1.06; 95\% Cl: 0.89,1.26), ADEs (RR 1.04; 95\% Cl: 0.96,1.13), QoL (standardised mean difference $=0.16 ; 95 \%$ Cl:-0.13, 0.45 ), cognitive function (weighted mean difference $=0.69 ; 95 \% \mathrm{Cl}:-1.25,2.64)$ and BPSD (RR 0.68; $95 \%$ Cl: 0.44 , 1.06) (2 studies).
\end{abstract}

Conclusion: Modest improvements in medication appropriateness were observed in the studies included in this systematic review. However, the effect on clinical measures was limited to drive strong conclusions.

Keywords: Medication optimisation, Intervention, Elderly, Systematic review, Aged care facility, Clinical outcomes, Meta-analysis

\footnotetext{
* Correspondence: phend@hotmail.com

${ }^{1}$ Medical school, University of Western Australia, Perth, Australia

Full list of author information is available at the end of the article
}

(c) The Author(s). 2020 Open Access This article is licensed under a Creative Commons Attribution 4.0 International License, which permits use, sharing, adaptation, distribution and reproduction in any medium or format, as long as you give appropriate credit to the original author(s) and the source, provide a link to the Creative Commons licence, and indicate if changes were made. The images or other third party material in this article are included in the article's Creative Commons licence, unless indicated otherwise in a credit line to the material. If material is not included in the article's Creative Commons licence and your intended use is not permitted by statutory regulation or exceeds the permitted use, you will need to obtain permission directly from the copyright holder. To view a copy of this licence, visit http://creativecommons.org/licenses/by/4.0/ The Creative Commons Public Domain Dedication waiver (http://creativecommons.org/publicdomain/zero/1.0/) applies to the data made available in this article, unless otherwise stated in a credit line to the data. 


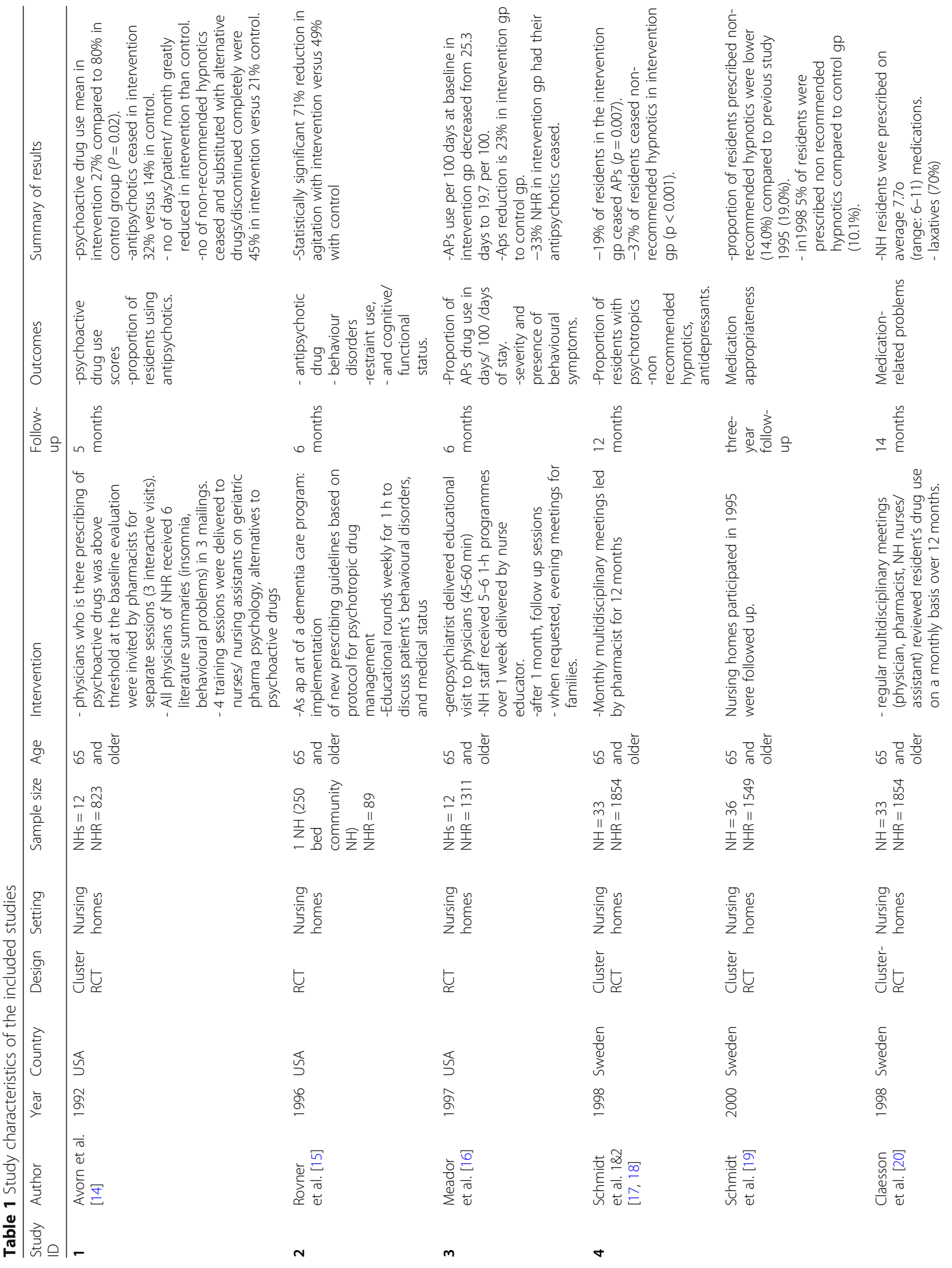




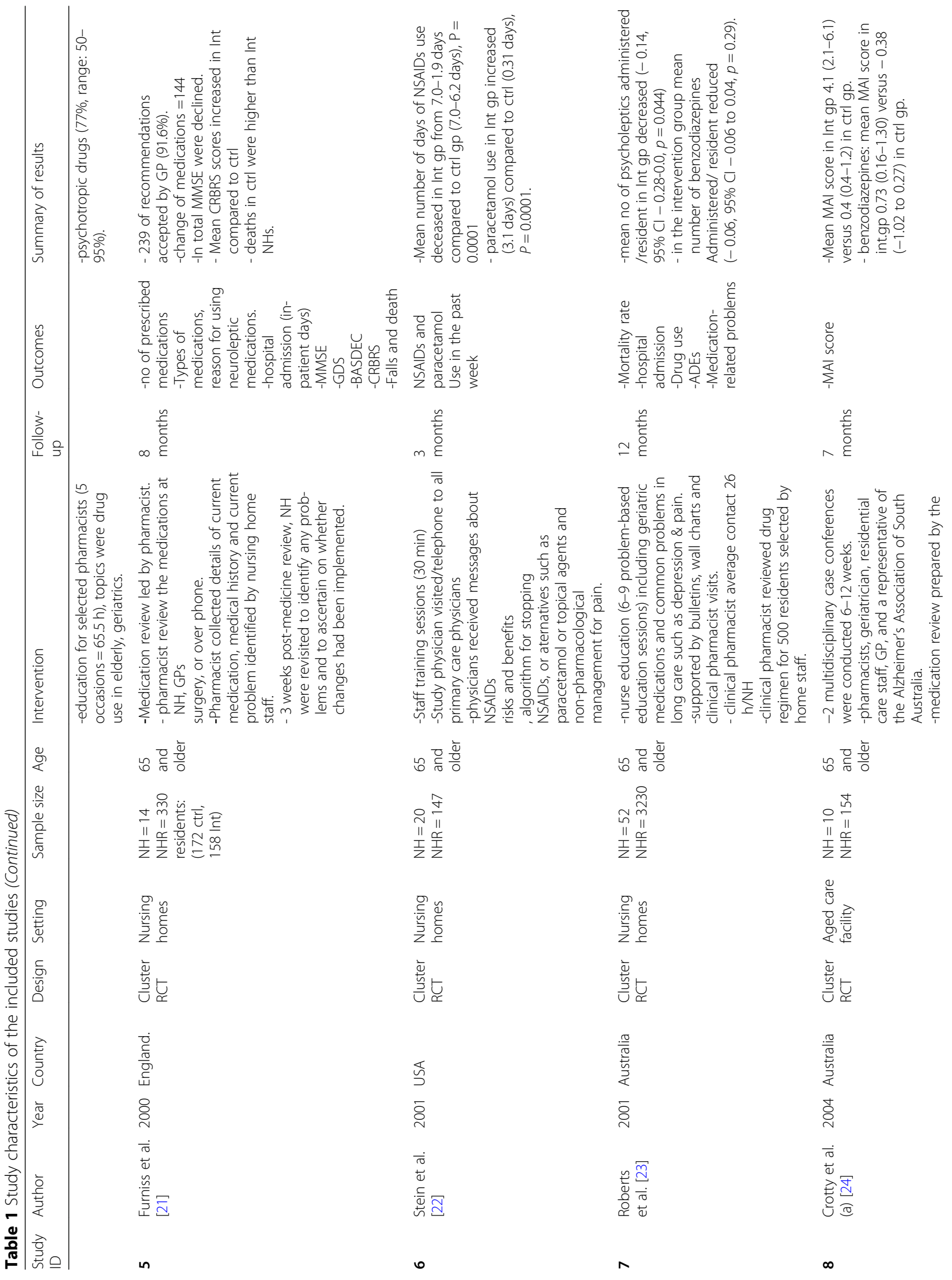




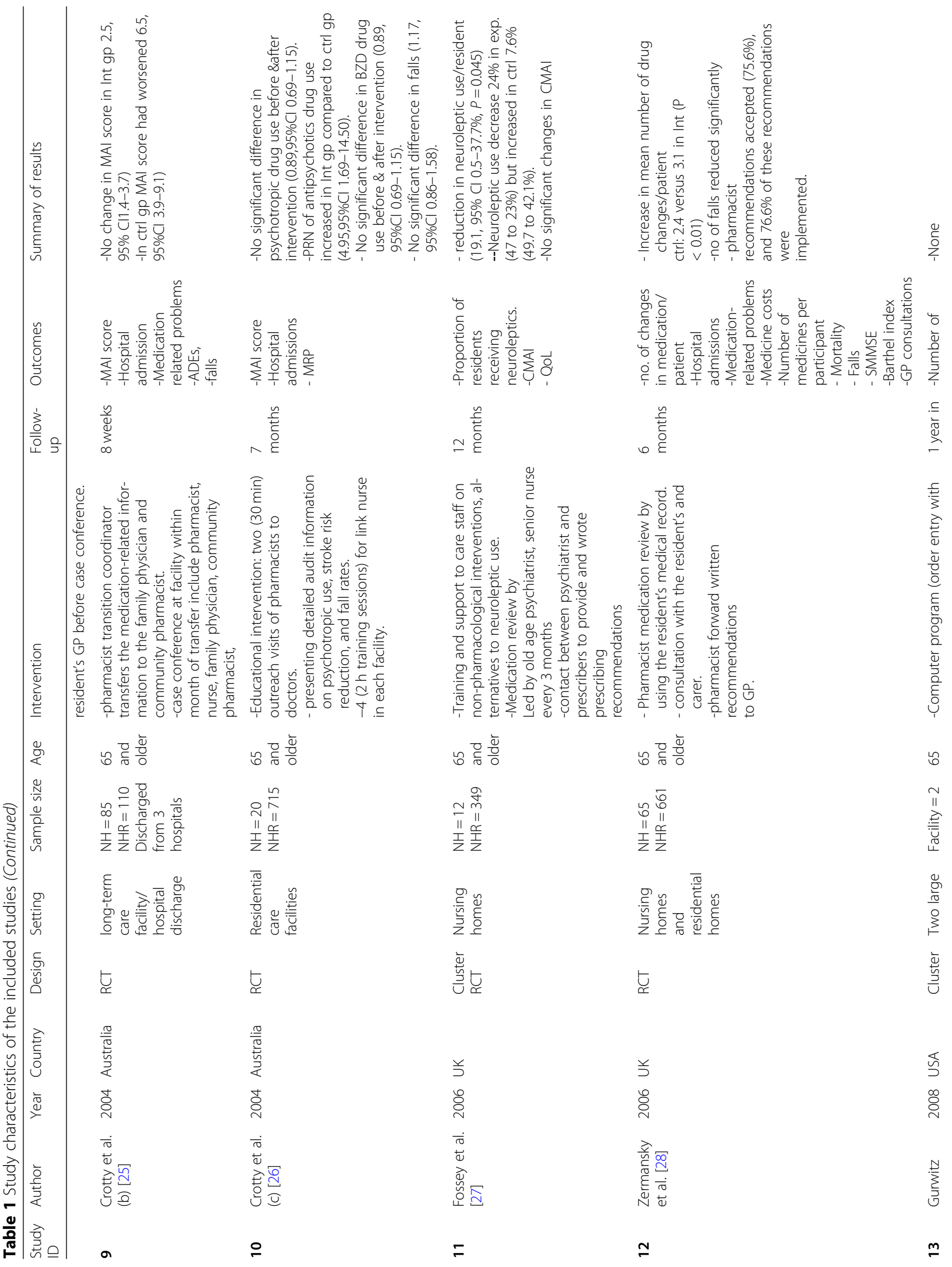




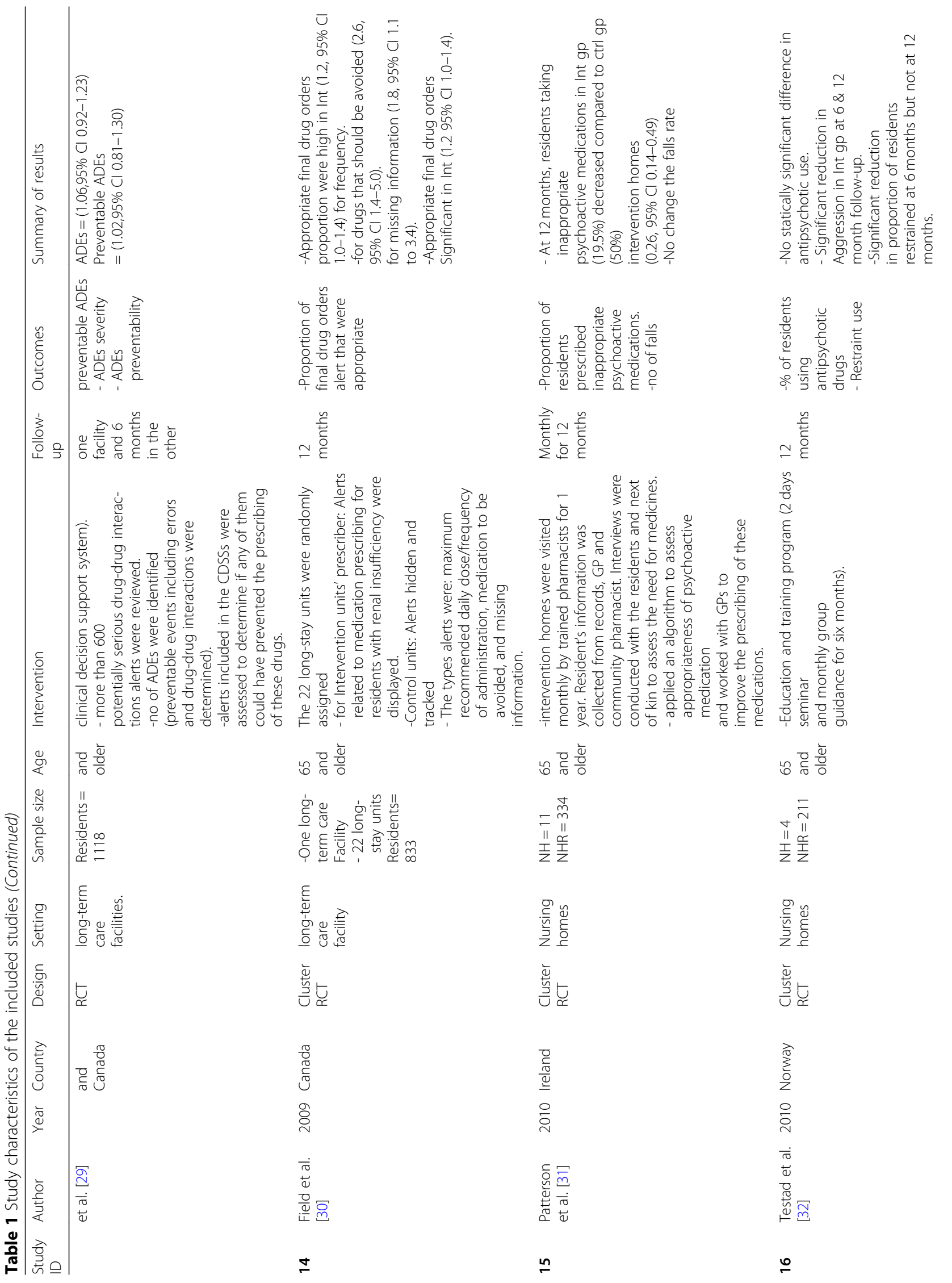




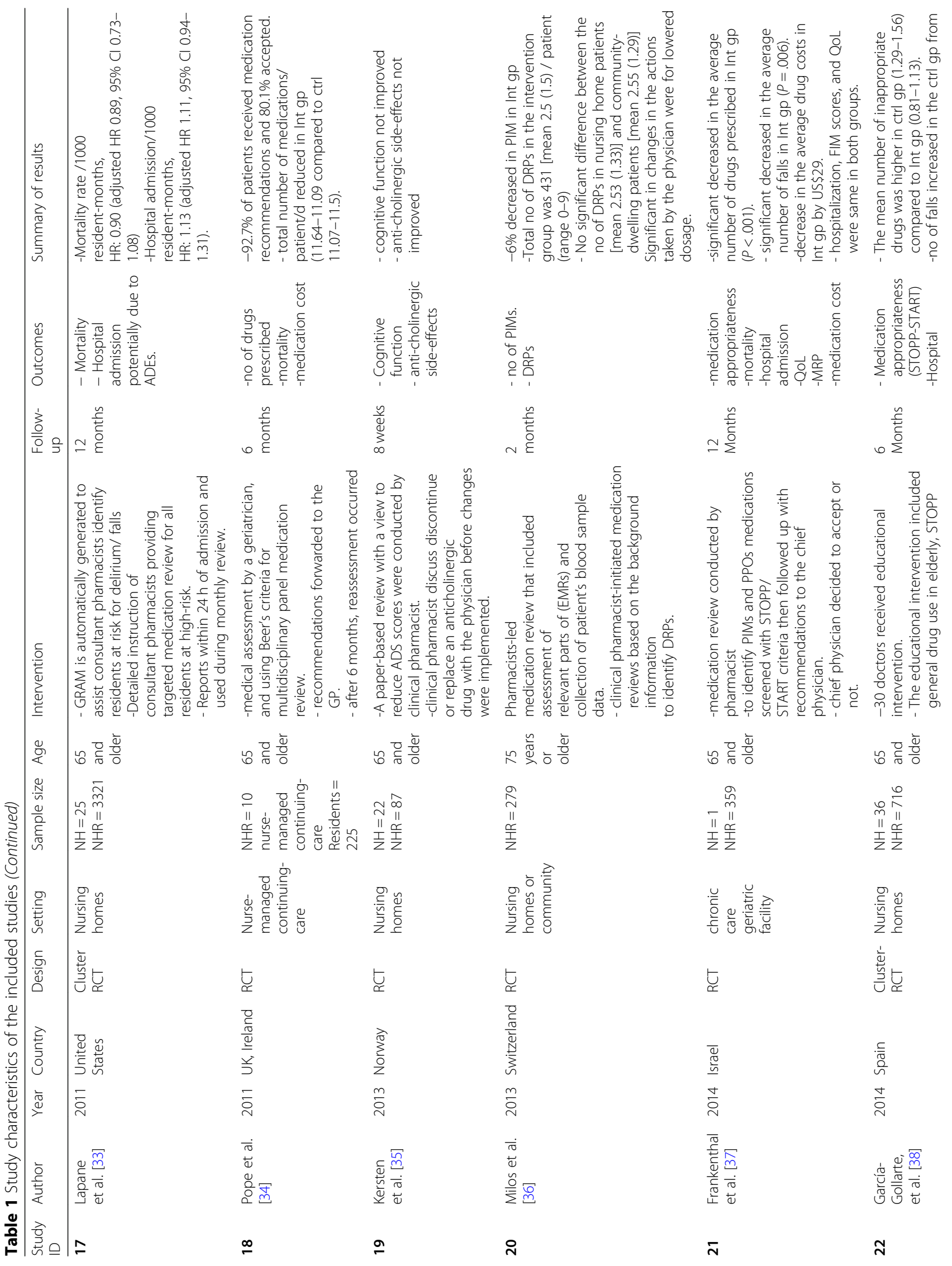




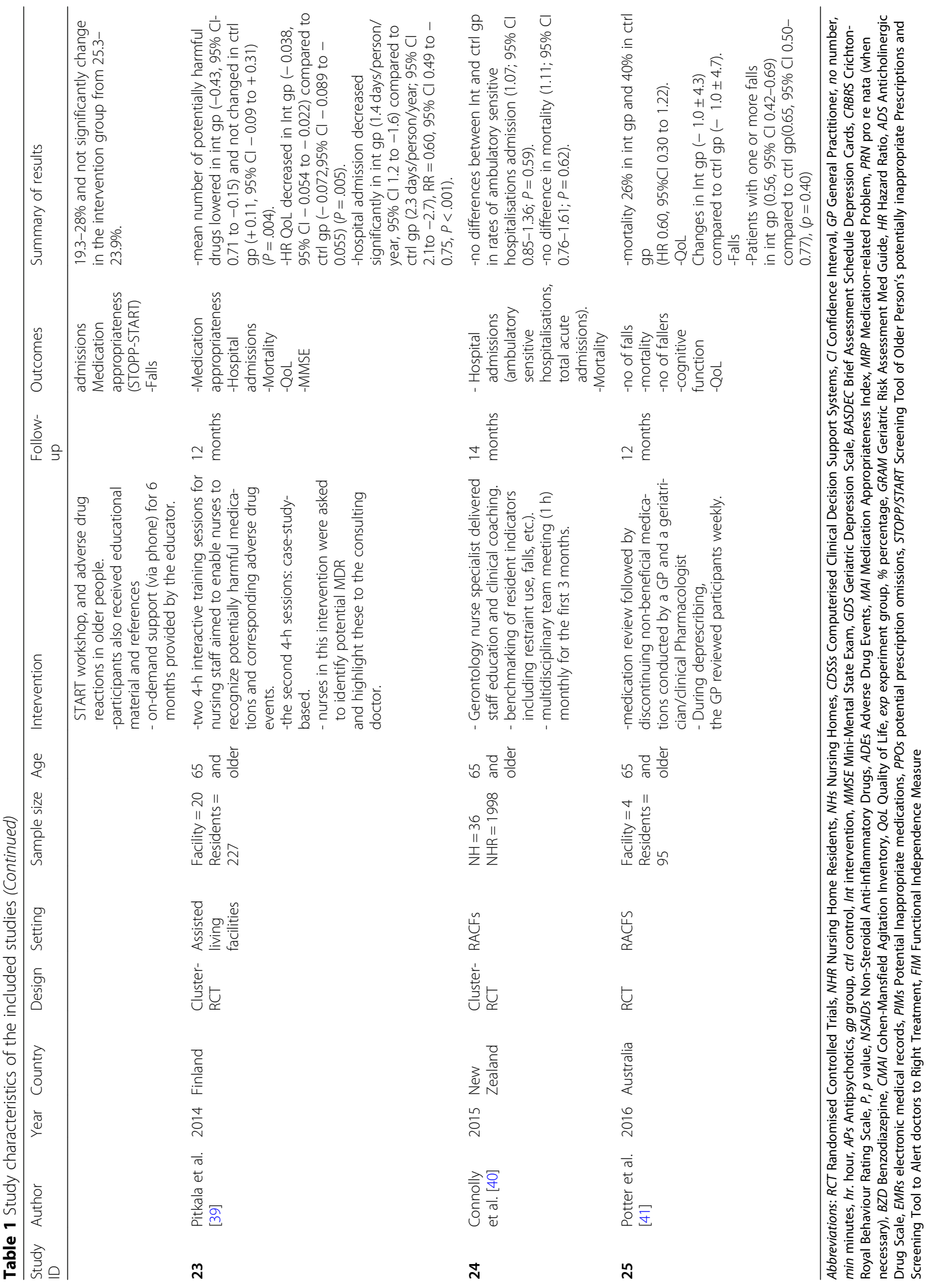




\section{Background}

Inappropriate medication prescription encompasses misprescribing, overprescribing, and underprescribing. Misprescribing involves the use of medication that significantly increases the risk of adverse drug events (ADEs) and involves incorrect dose, frequency, administration and duration. Use of medications that are likely to cause drug-drug interactions or drug-disease interactions is also an aspect of misprescribing. Overprescribing involves the use of medications without clear indications. Underprescribing is the omission of clinicallyindicated medication that may have potential benefit for treatment of the disease [1].

Residents of aged care facilities (RACFs) are often frail and have multiple comorbidities. On average RACF residents take more medications than younger age groups, and more than community-dwelling elderly with similar disease complications [2]. They are frequently prescribed multiple medications that can increase the risk of ADEs, morbidity and mortality [3, 4]. Moreover, the majority of these residents have dementia and the use of psychotropic drugs is typically high. Age-related changes in pharmacodynamics and pharmacokinetics, multiple comorbidities, and the presence of polypharmacy are the main factors often associated with ageing that makes optimisation of drug therapy a complex task. Furthermore,

Previous studies indicate that about $40 \%$ of prescriptions for RACF residents may be suboptimal or inappropriate [5]. Consequently, there is a heightened risk of adverse drug reactions (ADRs), hospitalisations, and medical expense $[3,6]$. Therefore, there is an urgent need to improve prescribing and to optimise drug therapy for older people living in care homes $[5,7]$.

Medication optimisation is a person-centred approach designed to ensure medication safety and improved clinical outcomes via effective use of medicine $[8,9]$. A range of interventions for optimisation of prescribed medications in RACFs have been developed to potentially optimise prescribing. These include medication review, education programs, the use of clinical decision support technology, and multidisciplinary case-conferencing. These interventions have been evaluated to determine the effect of optimising prescribing in nursing homes and in older people with dementia, but the results were not pooled statistically [10-12], and the nursing home specific data require updating. The 2011 review concluded that in nursing homes, educational interventions including academic detailing seems to show most promise [12]. The other 2011 review found that education and pharmacist drug review may reduce inappropriate drug use under certain circumstances [11]. The other 2018 review of 18 experimental studies specific to older people living with dementia in any setting concluded that the improvement of medication appropriateness is supported by emerging evidence, and the impact of these interventions on dementia patients' outcomes required more research [10].

We therefore aimed to systematically review the available interventions conducted by a health professional that aimed to increase the appropriateness of medications used in residential aged care facilities and to evaluate their effects on medication appropriateness and residents' clinical outcomes.

\section{Methods}

This systematic review was conducted and reported in compliance with the Preferred Reporting Items for Systematic Reviews and Meta-Analyses (PRISMA) guidelines [13]. A PRISMA checklist can be found in Additional file 1. The review was registered with the international prospective register of systematic reviews PROSPERO CRD42020148669.

\section{Data sources and search strategy}

An electronic search of the literature was conducted from inception to May 2019 using the following databases - MEDLINE, PubMed, Google scholar, PsycINFO. A combination of the following keywords and $\mathrm{MeSH}$ terms were used: "Optimize OR improve OR maximize OR optimization AND medication OR drugs OR medicines AND side effects OR safety OR administration OR review AND nursing homes OR residential OR aged care". The reference lists of the relevant articles and reviews were hand-searched to further identify any additional studies. The complete search strategy is presented in Additional file 2.

\section{Study selection}

The title and abstract of all retrieved articles were initially reviewed to find those potentially relevant to the study area. The abstract of the selected papers was assessed against five inclusion criteria: (i) randomised controlled trials (RCTs) and cluster randomised controlled trials (cRCTs); (ii) residents' age 60 and older; settings are residential aged care facility or nursing homes or residential continuing care hospitals; (iii) interventions to increase the appropriateness of medications used in nursing homes (iv) reported in English; (v) published between 1980 and 2019.

\section{Data extraction and quality assessment}

Details of the included articles were independently extracted by two authors (H.A, and L.F). Data included details of the authors, publication year, country, study design, age, setting, sample size, intervention, follow-up, outcomes, and summary of results. Table 1 depicts the study characteristics of the included studies. 


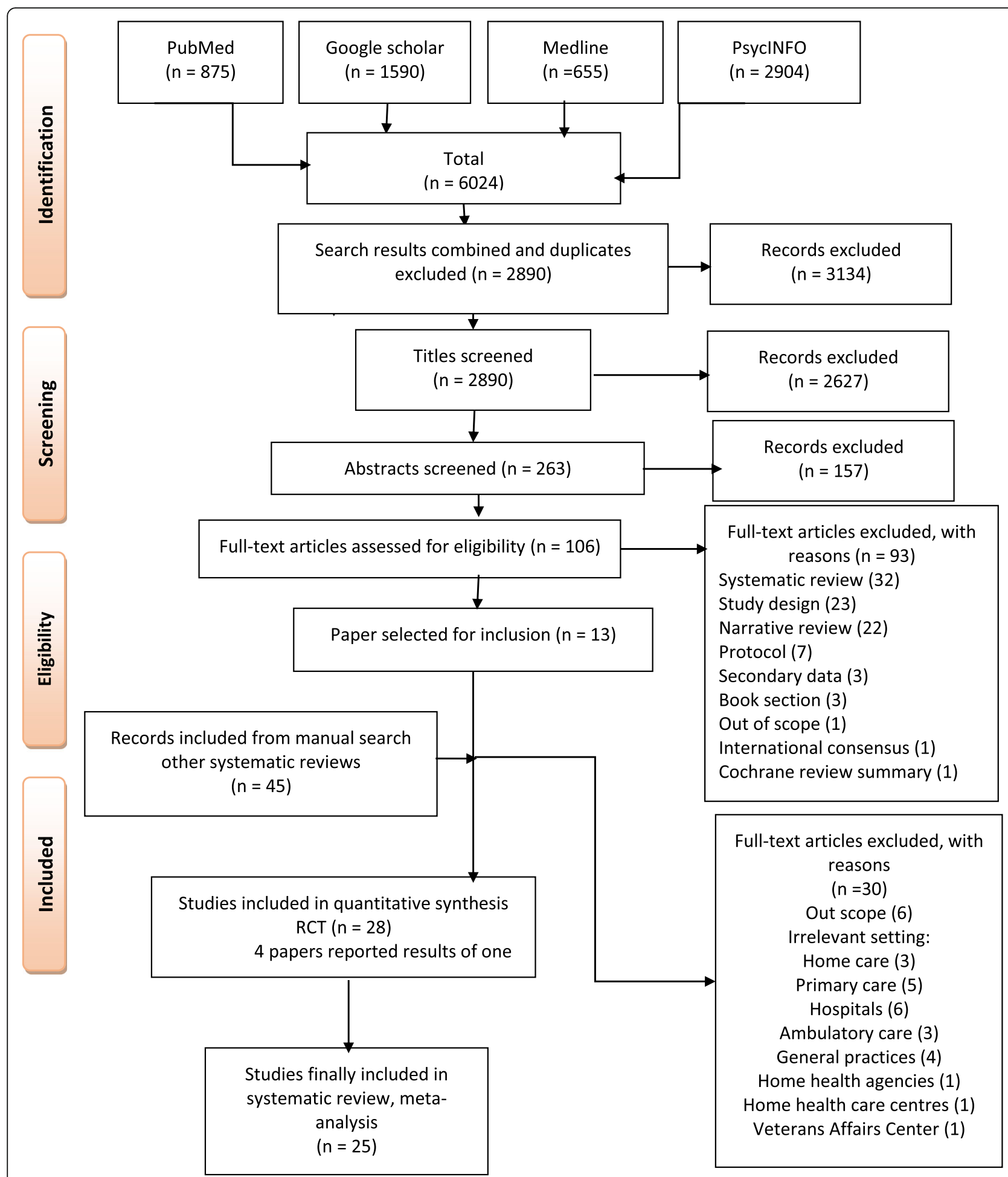

Fig. 1 PRISMA flow diagram

\section{Assessment of risk of Bias}

The quality of each article and risk of bias were assessed independently by the two reviewers (H.A, and L.F). For assessing risk of bias we used the Cochrane Collaboration's tool [42]. The studies assessed based on standard criteria: adequate sequence generation, allocation concealment, blinding of participants and personnel, blinding of outcome assessment, incomplete outcome data, selective reporting, and other bias. Risk of bias tables provided in RevMan v5.3 was used to assess reporting 
bias. See Risk of Bias in Included Studies Section (Figs. 2 and 3).

\section{Statistical analysis}

Outcome measures such as medication appropriateness, hospitalisation, mortality and other outcomes were assessed for heterogeneity and were pooled for metaanalysis using fixed effects methods if little heterogeneity was found or using random effects methods if heterogeneity was present $(P$ value $<.05)$. The software Review Manager (RevMan) version 5.3 (The Cochrane Collaboration, The Nordic Cochrane Centre, Copenhagen, Denmark) was used. The risk ratios (RR) for dichotomous outcomes with $95 \%$ confidence intervals (CIs) were calculated. Heterogeneity was measured by $I^{2}$. Continuous outcomes were expressed as mean difference (MD) and standardized mean difference (SMD) between groups with a $95 \%$ confidence interval $(95 \% \mathrm{CI})$. Funnel plots were used to assess possible publication bias (Additional file 3: Figs. S1 to S9). Effect estimates were considered statistically significant of the $p$ value was less than 0.05 (2 tailed).

\section{Results}

The literature search provided a total of 6024 potentially relevant publications. Following independent screening for eligibility, 106 articles were assessed for eligibility of which 25 RCTs and cRCTs were included in this systematic review. The flowchart of the literature search is represented in Fig. 1.

\section{Study design}

The design consisted of 15 studies [14, 17, 19-24, 27, 29-33, 38-40] comprising five cRCTs and 10 RCTs [15, $16,25,26,28,34-37,41]$.

\section{Country and settings}

Trials in residential aged care settings or residential continuing care hospitals (long-term care) were conducted in the USA $(n=5)[14-16,22,33]$, Australia $(\mathrm{n}=5)$ [23$26,41]$, UK $(n=3)[21,27,28]$, Norway $(n=2)[32,35]$, and one each in Canada [30], Israel [37], Sweden (4 papers reported results of one) [17-20], Finland [39], Spain [38], Switzerland [36], Ireland [31], New Zealand [40] and one combined between USA and Canada [29] and one combined between UK and Ireland [34].

\section{Participants}

Studies included involved older people living in residential aged care facilities aged 60 years and older with a mean age range of 81.2 to 87.2 years.

\section{Interventions}

Various interventions applied by pharmacist, physician or a multidisciplinary team (physicians, pharmacists, and nurses) in the included studies were evaluated. Methods to review residents' medications were presented in 12 studies [21, 23, 25, 28, 31, 33-38, 41]; nine studies [14$16,22,26,27,32,39,40]$ investigated the impact of staff education, four studies $[17,20,24,25,40]$ evaluated the implementation of multi-disciplinary case conferencing, and two studies $[29,30]$ evaluated computerised clinical decision support systems.

\section{Outcomes}

Most outcome measures in the reviewed studies were reported as (a) medication appropriateness $(n=16)$ [14$17,19,23-27,30,31,35-39]$, hospital admission $(n=$ 11) $[21,23,25,28,33,34,37-41]$, mortality $(n=9)[21-$ 23, 28, 33, 34, 37, 39, 40], medication-related problems $(n=7)[18,20,21,23,25,28,36,37]$, falls $(\mathrm{n}=7)[26-$ $28,31,33,38,41]$, quality of life $(n=5)[27,34,37,39$, 41], Behavioural and Psychological Symptoms of Dementia BPSD $(n=4)[15,16,27,32]$, ADEs $(n=2)[25$, $29]$, and cognitive function $(n=2)[15,35]$.

\section{Medication appropriateness}

Medication appropriateness was assessed in 11,470 residents encompassing 16 RCTs [14-17, 19, 23-27, 30, 31, 35-39] by different tools including Medication Appropriateness Index (MAI) [24-26], STOPP-START criteria [37, 38], indicators of appropriate neuroleptic prescribing in nursing homes [27], Beers criteria, Anticholinergic Drug Score (ADS), number of psychotropic medications and non-steroidal anti-inflammatory drugs (NSAIDs( [39].

\section{Other outcomes \\ Hospital admission}

Eleven studies [21, 23, 25, 28, 33, 34, 37-41] specified hospital admission as an outcome measure. Furniss et al. [21] reported in-patient days as hospital admission. Roberts et al. [23] investigated the proportion of hospitalised residents. Crotty et al. [25] reported hospital usage based on unplanned visits to emergency department and hospital readmission. Zermansky et al. [28] reported hospitalisation rate during a 6-month period per resident. Lapane et al. [33] investigated any hospitalisation and potential ADE-related hospitalisation in a randomised cluster trial. Pope et al. [34] reported the number of admissions to acute hospital. Frankenthal et al. [37] reported hospital admissions. Garcia-Gollarte et al. [38] reported the total number of days spent in hospital. Pitkala et al. [39] reported hospital days/resident/year. Connolly et al. [40] reported all acute admissions and ambulatory sensitive hospitalisations. Potter et al. [41] reported hospital admission as the 


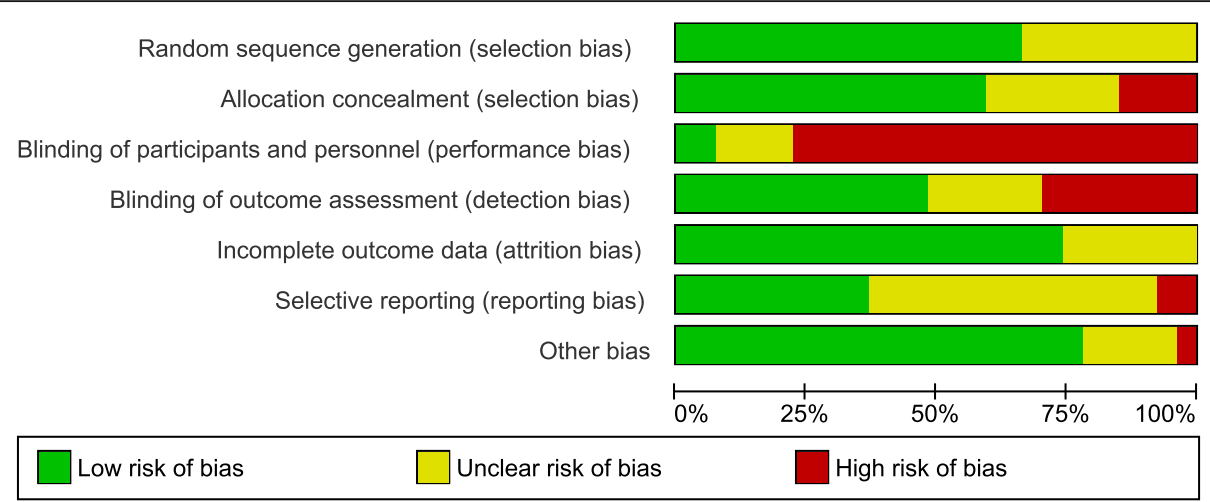

Fig. 2 Risk of bias graph

proportion of residents experiencing an unplanned hospital admission.

\section{Mortality}

Nine studies [21-23, 28, 33, 34, 37, 39, 40] included mortality as an outcome measure. Furniss et al. [21] reported mortality as a number of deaths over 8-months, by Zermansky et al. [28] over 6-months. The number of deaths was reported by Stein et al. [22] over a 3-month evaluation period, by Pope et al. [34] over a 6-month period, and by Frankenthal et al. [37] over 1 year. Roberts et al. [23] reported residents' cumulative survival and death proportion for 1 year. Lapane et al. [33] calculated the average percentage of mortality per 1000 person-months. Pitkala et al. [39] used a Cox proportional hazard model to calculate hazard ratios. Connolly et al. [40] reported death risk ratio over 14 months.

\section{Falls}

Seven studies [26-28, 31, 33, 38, 41] included falls as an outcome measure. Crotty et al. [26] calculated the percentage of residents who fell in 3 months prior. Fossey et al. [27] reported the proportion of residents who had at least one fall over a 12-month period. Zermansky et al. [28] reported number of falls over 6 months. Patterson et al. [31] calculated falls rate per 100 residentmonths. Lapane et al. [33] reported the number of people falling over 12 months. Garcia-Gollarte et al. [38] reported the number of falls and fallers postintervention. Potter et al. [41] reported the proportion of patients with one or more falls.

\section{Medication - related problems}

Seven studies $[18,20,21,23,25,28,36,37]$ included medication - related problems as an outcome measure. Claesson and Schmidt et al. $[18,20]$ reported the type and frequency of drug-related problems discussed by clinical teams and their recommendations. Furniss et al. [21] reported the total number of recommendations made by the pharmacist, and the accepted recommendations by the general physician (GP) and the actual changes in medications. Roberts et al. [23] calculated the number of drug changes. Crotty et al. [25] categorised medication-related problems to different categories such as high dose, administration time and no indication. Zermansky et al. [28] measured the recommendations made by the pharmacist against the number of accepted/rejected recommendations of the doctor. Milos et al. [36] measured the percentage of medications changed. Frankenthal et al. [37] measured the number of recommendations accepted by the GP according to the STOPP-START criteria. There was no extractable data for this outcome and therefore meta-analysis was not performed.

\section{Quality of Life (QoL)}

Five studies [27, 34, 37, 39, 41] reported patient Quality of Life (QoL). Fossey et al. [27] reported rating for wellbeing in residents. Pope et al. [34] measured QoL by asking patients with Abbreviated Mental Test Score (AMTS $\geq 8$ ) or staff who were familiar with the patient about whether the intervention had been of benefit. Frankenthal et al. [37] used the Medical Outcomes Study 12-item Short-form Health survey (SF-12). Pitkala et al. [39] used the 15-dimensional instrument of healthrelated QoL (15D). Potter et al. [41] used self-reported QoL assessed with Quality of Life in Alzheimer's Dementia (QOLAD).

\section{Behavioural and Psychological Symptoms of Dementia (BPSD)}

Four studies [15, 16, 27, 32] assessed Behavioural and Psychological Symptoms of Dementia (BPSD). Rovner et al. [15] reported behaviour disorder. Fossey et al. [27] reported aggression events in past 12 months and Testad et al. [32] used the Cohen-Mansfield agitation inventory tool (CMAI) to measure agitated behaviour of residents. Meador et al. [16] used Nursing Home Behaviour Problem Scale (NHBPS). 


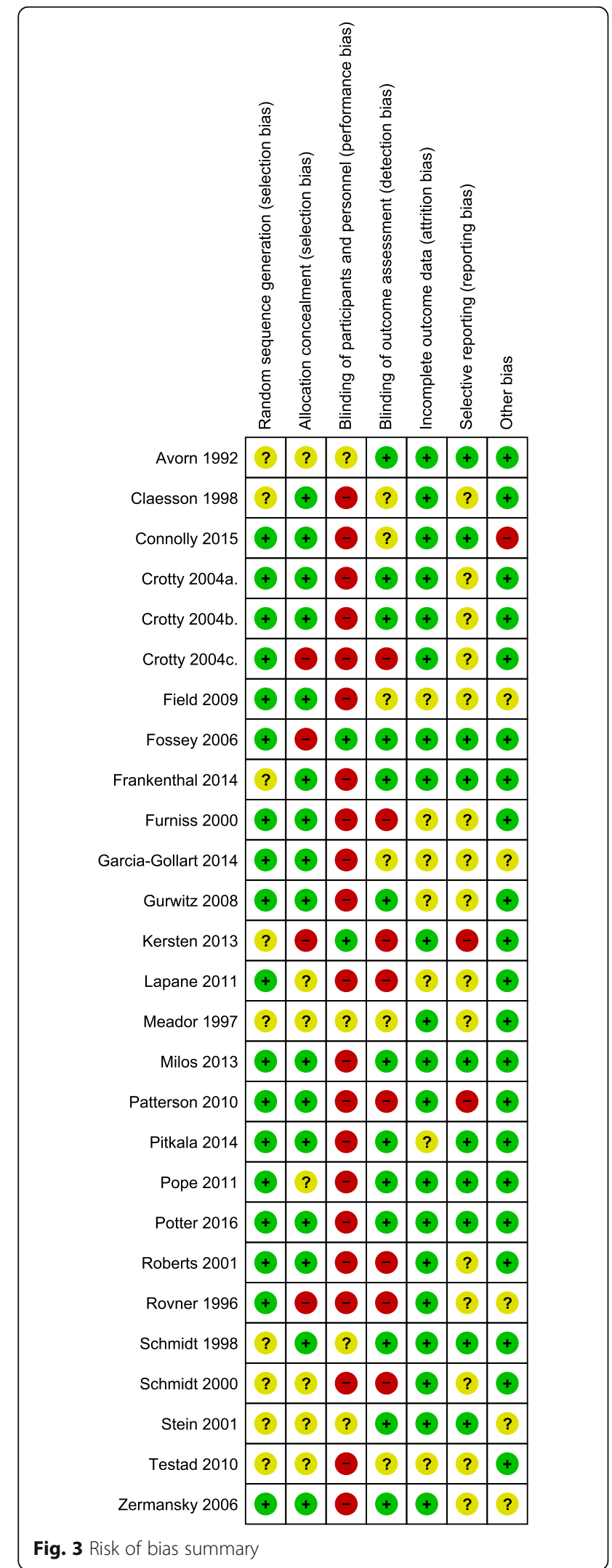

ADEs

Two studies $[25,29]$ reported ADEs. One study defined $\mathrm{ADE}$ as an injury resulting from the use of a drug [29]. Crotty et al. [25] investigated number of ADEs during the 8-week follow-up period.

\section{Cognitive function}

Two studies [15, 35] included cognitive function as an outcome measure. Rovner et al. [15] used the Norwegian version of the global cognitive test Mini-Mental Sate Examination (MMSE) to assess cognition. Kersten et al. [35] used the Consortium to Establish a Registry for Alzheimer's Disease (CERAD)'s 10-word list test for delayed recall and recognition and MMSE.

\section{Risk of bias in included studies}

Assessment of the risk of bias is summarised in (Figs. 2 and 3). Except for nine studies with unclear risk [14, 16, $17,19,20,22,32,35,37]$, the remaining 16 studies had low risk of selection bias. Performance bias was high in $21(77.8 \%)$ studies [15, 19-21, 23-26, 28-34, 36-41]; detection bias was high in eight $(29.6 \%)$ studies $[15,19,21$, $23,26,31,33,35]$, and allocation concealment was found in four (14.8\%) studies [15, 26, 27, 35]. In most of the studies, blinding of participants and staff was not possible due to the nature of the intervention.

\section{Effectiveness of the interventions Medication appropriateness}

Meta-analysis of medication appropriateness (Fig. 4) including 6754 residents $[15,17,23-27,30,31,37-39]$ showed a significant improvement on medication appropriateness (RR 0.71; 95\% confidence interval (CI): 0.60, 0.84 , despite high heterogeneity $\left(P<0.00001 ; I^{2}=\mathbf{9 1} \%\right)$. This outcome was assessed for the intervention subtypes of staff education (RR 0.66, 95\% CI:0.43, 1.01), implementation of multi-disciplinary case conferencing (RR 0.97,95\% CI:0.92, 1.03) computerised clinical decision support systems (RR 0.78, 95\% CI:0.64, 0.95) and medication review (RR 0.62 95\% CI:0.41, 0.93) (See Fig. 5).

The standardised mean difference of medication appropriateness scales for the remaining two Crotty et al. studies [24, 25] was calculated separately (standardised mean difference $=-0.67 ; 95 \% \mathrm{CI}:-0.97,-0.36$ ) with a heterogeneity of $I^{2}=3 \%$.

\section{Other outcomes}

\section{Hospital admission}

Meta-analysis of hospital admission (Fig. 6) as an outcome measure investigated in 11,272 residents resulted in the analysis of eight studies $[25,28,33,34,37,38,40$, 41] (10,610 residents), which showed that interventions have no effect on hospital admission $\mathrm{RR}=1.00,95 \% \mathrm{CI}$ : $0.93,1.06$ ) with a heterogeneity of $I^{2}=0 \%$. 


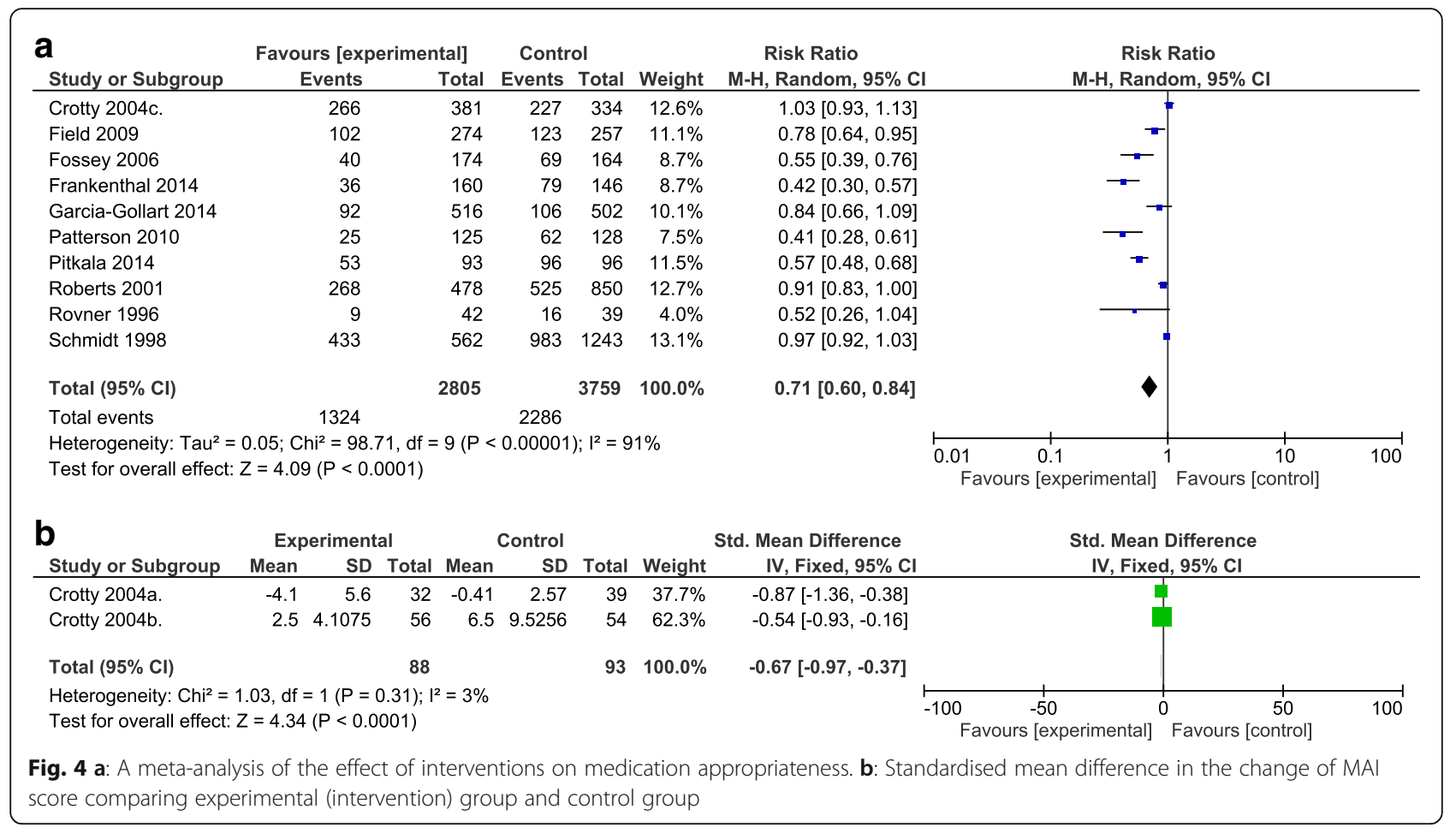

\section{Mortality}

Meta-analysis of mortality (Fig. 7) as an outcome measure investigated in 13,675 residents $[21-23,28,33,34$, $37,39,40]$ showed no significant difference between the intervention group and control group (RR 0.98, 95\% CI: $0.86,1.11, P=0.07)$ with a heterogeneity of $I^{2}=43 \%$.

\section{Falls}

Meta-analysis of falls (Fig. 8) as an outcome measure investigated in 9382 residents $[26-28,31,33,38,41]$ showed that interventions had no effect on falls $(R R=$ 1.06; 95\%CI: $0.89,1.26)$ with a heterogeneity of $I^{2}=87 \%$.

\section{Medication- related problems}

Claesson and Schmidt et al. [18, 20] found 819 medication -related problems in 395 participants resulting in an action taken in $90 \%$ (737) with withdrawal of a drug in 368 (45\%) and change of medications in 162 (20\%). Furniss et al. [21] reported that 239 (92\%) of 261 recommendations were accepted by the GP resulting in change in therapy in 144 patients. The most common reasons for recommendations (33\%) were the medication indication was no longer present. Roberts et al. [23] found that medication reviews resulted in changes to medications in 54 (39\%) of residents. Crotty et al. [25] reported that the most common medication-related problem identified in control and intervention groups was that the residents were allocated to a new family physician when transfer to long-term care facility $(n=35,62.5 \%$ intervention; $n=41,75.9 \%$ control). Zermansky et al. [28] found a significant difference in the mean number of drug changes per resident (mean 3.1, SD $=2.7$ for intervention and mean $2.4, \mathrm{SD}=2.6$ for control $)(P<0.0001)$. Milos et al. [36] found similar number of drug-related problems between community-dwelling patients (mean 2.55, SD = 1.29 ) and nursing home residents (mean $2.53, \mathrm{SD}=1.33$ ) $(p=0.767) .56 \%$ of drug-related problems resulted in an action taken and change of medications (mean 1.44, $\mathrm{SD}=1.33$ ) with no difference between the community dwelling and the nursing home patients $(p=0.946)$. Frankenthal et al. [37] made 327 recommendations - 245 in 129 residents based on STOPP and 82 in 65 residents based on START. The physician accepted $82.4 \%$ of STOPP recommendations and $92.6 \%$ of START recommendations.

\section{Quality of Life (QoL)}

Meta-analysis of quality of life (Fig. 9) outcomes in 570 residents, of a total of 1141 residents that included QoL as an outcome measure, found that the interventions had no effect on residents' QoL (standardised mean difference $=0.1695 \%$ CI:-0.13, 0.45) with a heterogeneity of $I^{2}=57 \%$ between trials $[37,39,41]$. Pitkala et al. [39] reported that health-related QoL in the intervention group $(-0.038,95 \%$ CI: $-0.054,-0.022)$ declined more slowly than in control group during 12-month follow-up (0.072, 95\% CI: - 0.089, - 0.055). Frankenthal et al. [37] found no significant difference between groups in the 


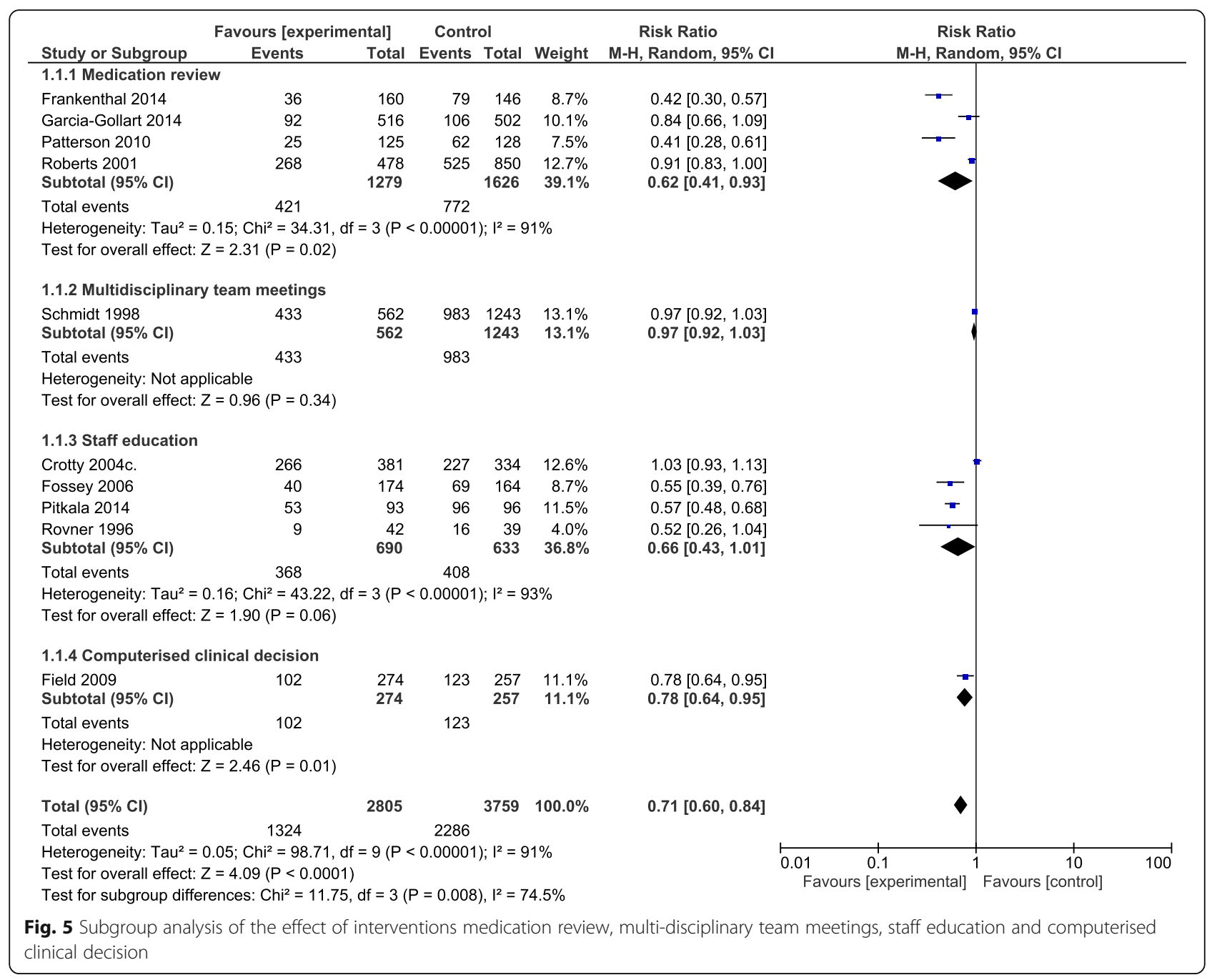

physical average score (intervention mean 33.1 \pm 8.1 , control mean $33 \pm 8.3, p=0.09$ ) and mental components (intervention mean $37.7 \pm 1.7$, control mean $39.6 \pm 11.3$ $p=0.70)$ of the SF-12 questionnaire.
BPSD

Of 1941 residents examined, pooled analysis of BPSD of two studies [15, 27] comprising 419 residents showed no

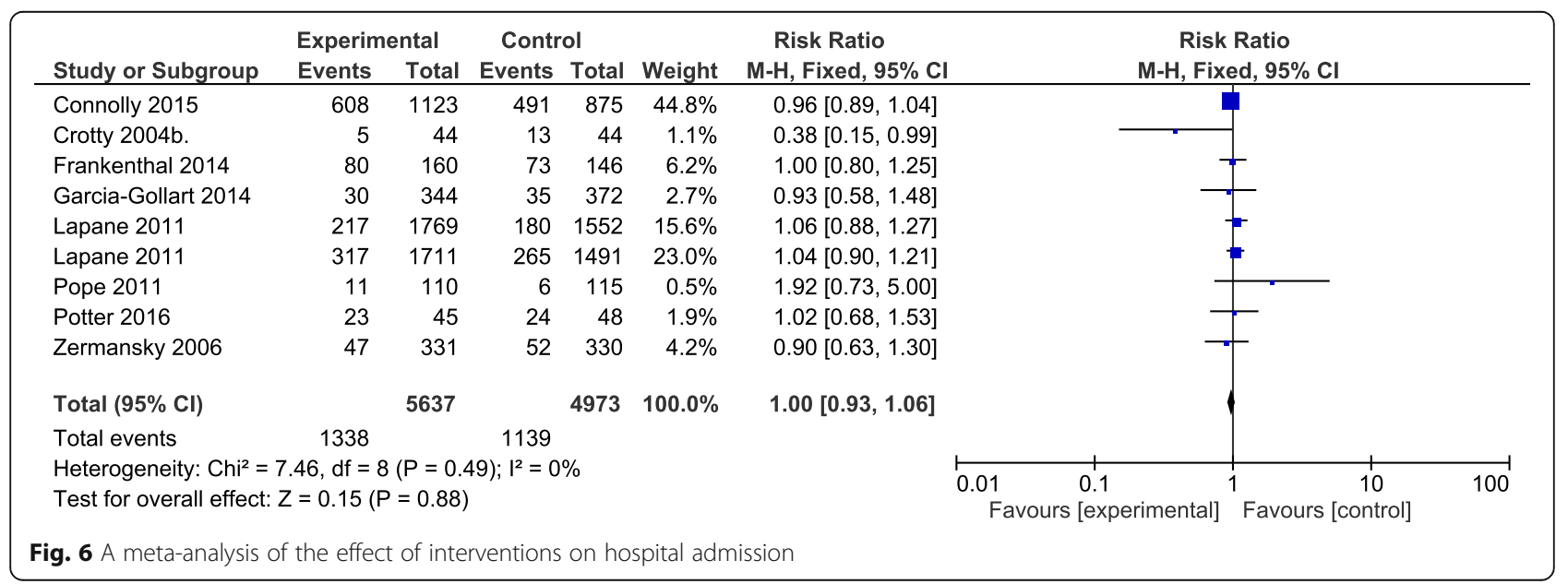




\begin{tabular}{|c|c|c|c|c|c|c|c|c|c|}
\hline Study or Subgroup & \multicolumn{2}{|c|}{ Experimental } & \multicolumn{2}{|c|}{ Control } & Weight & $\begin{array}{c}\text { Risk Ratio } \\
\text { M-H, Random, } 95 \% \mathrm{Cl} \\
\end{array}$ & \multicolumn{3}{|c|}{\begin{tabular}{ll}
\multicolumn{1}{c}{ Risk Ratio } \\
M-H, Random, $95 \% \mathrm{Cl}$
\end{tabular}} \\
\hline Connolly 2015 & 240 & 1123 & 179 & 875 & $19.7 \%$ & $1.04[0.88,1.24]$ & + & & \\
\hline Frankenthal 2014 & 15 & 183 & 17 & 176 & $3.4 \%$ & $0.85[0.44,1.65]$ & & & \\
\hline Furniss 2000 & 4 & 136 & 14 & 158 & $1.4 \%$ & $0.33[0.11,0.98]$ & & & \\
\hline Lapane 2011 & 114 & 1769 & 98 & 1552 & $13.7 \%$ & $1.02[0.79,1.33]$ & & & \\
\hline Lapane 2011 & 211 & 1711 & 215 & 1491 & $19.4 \%$ & $0.86[0.72,1.02]$ & $=$ & & \\
\hline Pitkala 2014 & 39 & 118 & 24 & 109 & $6.9 \%$ & $1.50[0.97,2.32]$ & & $=$ & \\
\hline Pope 2011 & 17 & 110 & 11 & 115 & $3.0 \%$ & $1.62[0.79,3.29]$ & - & & \\
\hline Roberts 2001 & 216 & 905 & 617 & 2325 & $22.8 \%$ & $0.90[0.79,1.03]$ & t & & \\
\hline Stein 2001 & 2 & 81 & 6 & 77 & $0.7 \%$ & $0.32[0.07,1.52]$ & & & \\
\hline Zermansky 2006 & 51 & 331 & 48 & 330 & $9.0 \%$ & $1.06[0.74,1.52]$ & & & \\
\hline Total $(95 \% \mathrm{Cl})$ & & 6467 & & 7208 & $100.0 \%$ & $0.98[0.86,1.11]$ & 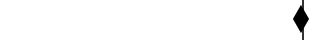 & & \\
\hline Total events & 909 & & 1229 & & & & & & \\
\hline $\begin{array}{l}\text { Heterogeneity: } \mathrm{Tau}^{2}= \\
\text { Test for overall effect: }\end{array}$ & $\begin{array}{l}0.01 ; \mathrm{Chi}^{2} \\
\mathrm{Z}=0.36(\end{array}$ & $\begin{array}{l}=15.73, \\
=0.72)\end{array}$ & $d f=9(P$ & $=0.07$ & $; I^{2}=43 \%$ & & $\begin{array}{lll}0.01 & 0.1 & 1 \\
& \text { Favours [experimental] }\end{array}$ & $\begin{array}{c}10 \\
\text { Favours [control] }\end{array}$ & 100 \\
\hline
\end{tabular}

significant change after the intervention (RR 0.68, 95\% CI: 0.44,1.06; $I^{2}=0 \%$ ) (Fig. 10).

\section{ADEs}

Of the 1206 residents [25, 29] examined for ADEs after the intervention. Neither of the two RCTs reported any statistically significant differences in ADEs between the intervention and control groups. The RR for all ADEs was 1.04 (95\% CI: 0.96,1.13; $I^{2}=0 \%$ ) (Fig. 11).

\section{Cognitive function}

Meta-analysis of 145 residents [15, 35] indicated that the interventions had no effect on cognitive function (weighted mean difference $=0.69,95 \% \mathrm{CI}:-1.25,2.64$ ) (Fig. 12). No heterogeneity was detected between trials $\left(I^{2}=0\right)$.

\section{Discussion}

This systematic review examined how a wide variety of interventions optimise medications prescribed in nursing homes, when applied either individually or through multi-faceted approaches. Our meta-analysis of available data showed that the interventions implemented in the included studies can improve medication appropriateness in older residents, although heterogeneity was high among included studies. Whilst these results were promising, the impact on the residents' clinical outcomes was undetectable. There was limited evidence for effectiveness of interventions in reducing hospitalisation, allcause mortality, falls, ADEs, cognitive function or BPSD.

There are several published systematic reviews on clinical outcomes of different interventions conducted in aged care homes. In a review by Forsetlund and colleagues [11], the authors found that both educational outreach/educational interventions and medication review by pharmacists under certain situations could reduce inappropriate drug use in nursing homes. However, they reported that the evidence was of poor quality and too low to assess the effect of the interventions on health outcomes. A review by Loganathan et al. [12] grouped the interventions into four

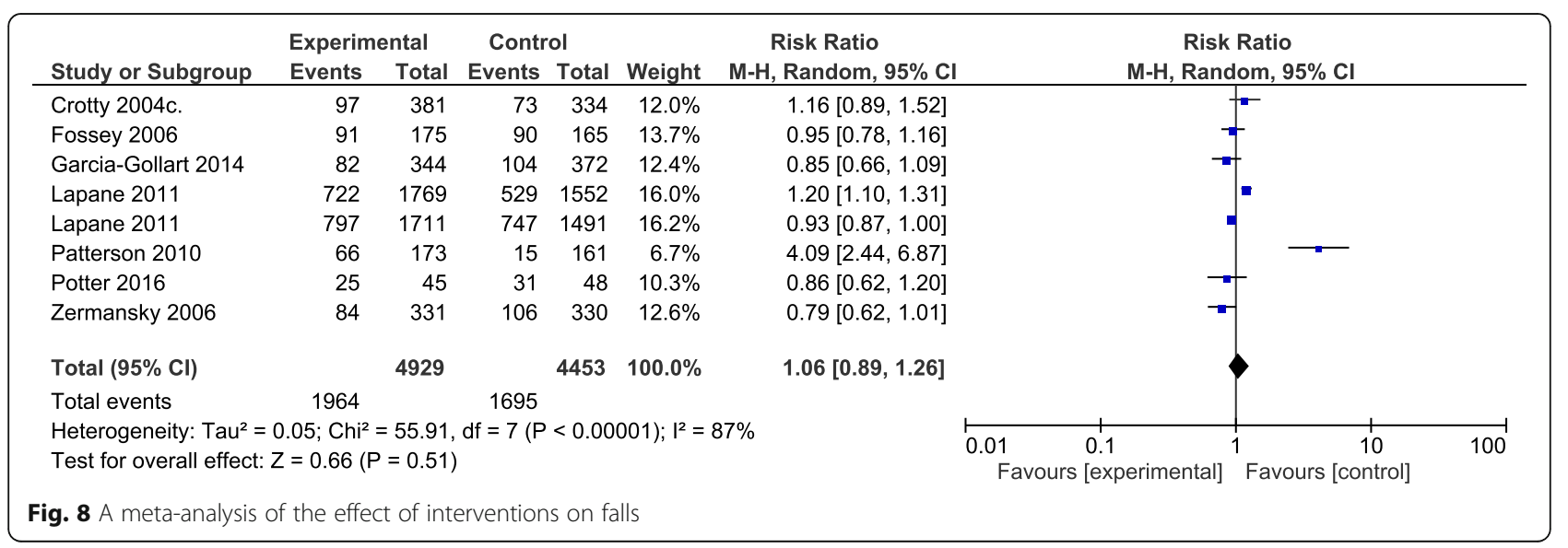




\begin{tabular}{|c|c|c|c|c|c|c|c|c|c|c|c|}
\hline \multirow[b]{2}{*}{ Study or Subgroup } & \multicolumn{3}{|c|}{ Experimental } & \multicolumn{3}{|c|}{ Control } & \multicolumn{2}{|r|}{ Std. Mean Difference } & \multirow{2}{*}{\multicolumn{3}{|c|}{$\begin{array}{l}\text { Std. Mean Difference } \\
\text { IV, Random, } 95 \% \mathrm{Cl}\end{array}$}} \\
\hline & Mean & SD & Total & Mean & SD & Total & Weight & IV, Random, $95 \% \mathrm{Cl}$ & & & \\
\hline Frankenthal 2014 & 33.1 & 8.1 & 160 & 33 & 8.3 & 146 & $44.8 \%$ & $0.01[-0.21,0.24]$ & 4 & & \\
\hline Pitkala 2014 & -0.038 & 0.0878 & 118 & -0.072 & 0.0895 & 109 & $40.6 \%$ & $0.38[0.12,0.65]$ & 1 & $\mathbf{I}$ & \\
\hline Potter 2016 & -1 & 4.3 & 22 & -1 & 4.7 & 15 & $14.5 \%$ & $0.00[-0.66,0.66]$ & & & \\
\hline Total $(95 \% \mathrm{Cl})$ & & & 300 & & & 270 & $100.0 \%$ & $0.16[-0.13,0.45]$ & & & \\
\hline \multicolumn{7}{|c|}{$\begin{array}{l}\text { Heterogeneity: } \mathrm{Tau}^{2}=0.03 ; \mathrm{Chi}^{2}=4.65, \mathrm{df}=2(P=0.10) ; \mathrm{I}^{2}=57 \% \\
\text { Test for overall effect: } Z=1.10(P=0.27)\end{array}$} & & & $\begin{array}{ll}-100 & -50 \\
& \text { Favours [experimental] }\end{array}$ & $\begin{array}{c}50 \\
\text { Favours [control] }\end{array}$ & 100 \\
\hline
\end{tabular}

groups (staff education including academic detailing, multi-disciplinary team meetings, medication review, and computerised clinical decision support system). No one interventional strategy was found to be effective. However, the most promising intervention seems to be education including academic detailing. That review reported that multifaceted interventions are likely to be required to improve prescribing in care homes [12]. A narrative review by Shafiee et al. [10], which included 18 studies, seven of them RCTs, found that the interventions may improve medication appropriateness in people with dementia in any settings, but the evidence for the effect of the interventions on health outcomes remained uncertain.

Our findings on clinical outcomes are in line with that of previous reviews [43, 44], which found no evidence for the interventions impacting resident's clinical outcomes such as ADEs, mortality, QoL and hospital admission. Since the elderly often exhibit non-specific clinical symptoms such as depression, constipation, falls and confusion, it is difficult to detect ADEs as opposed to the general condition of the residents. Another possible reason for the lack of significant effect of interventions on falls and ADEs may be the potential for underreporting of incidents that were obtained from nursing records. The lack of effect of interventions on QoL in the treatment group compared to the control may be attributed to the wide variation in the length of the follow up period (3-12 months) [43].

Interventions that focus on individual team members may had limited effectiveness in busy clinical environment. For example, the educational intervention delivered by a pharmacist [26] failed to have any significant effect on major outcomes. The investigators demonstrated that the lack of effect was attributed to staff attrition, short study duration, and not all the physicians in the recruited homes participated in the study.

Very few of the interventions were based on strong theoretical foundations. An exception was the educational study by Pitkälä et al. [39], who suggested that the use of constructive learning theory to recognise potentially harmful medications was more likely to change practice in healthcare than using lectures alone. Deficits in the education of health careworkers were thought to be important. Forsetlund et al. [11] suggested that health care providers receive inadequate training in geriatric medications in their education. Therefore, any intervention for minimising medications usually requires some form of education.

Although our primary focus was on clinical outcomes, some interventions demonstrated a decrease in medication-related costs. Frunsis et al. [21] reported a reduction in the cost of medicine per resident over 4 months period by 27.47 GB Pounds in the intervention group. Roberts et al. [23] reported savings in drug cost (64 AUD/ resident/year in intervention group) in the clinical pharmacy program. Frankenthal et al. [37] found a significant reduction in the average monthly costs of medications in the intervention group ILS $279 \pm 171.9$ compared to baseline ILS $382.7 \pm 279(P<0.001)$ at 12 months follow-up period. Pope et al. [34] reported a net reduction in medication cost in intervention group over a 6-month period. While, Crotty et al. [24] reported similar Pharmaceutical Benefit Scheme (PBS) monthly drug costs of regular medications between groups (mean AUD 359 in intervention versus AUD 303 in control $(P=0.837)$. These interventions require resources and

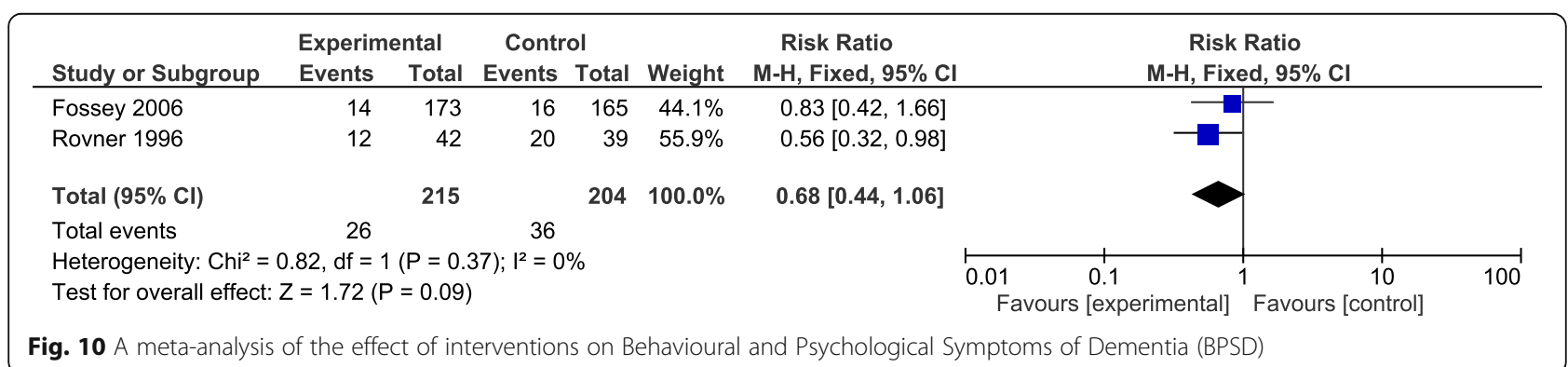




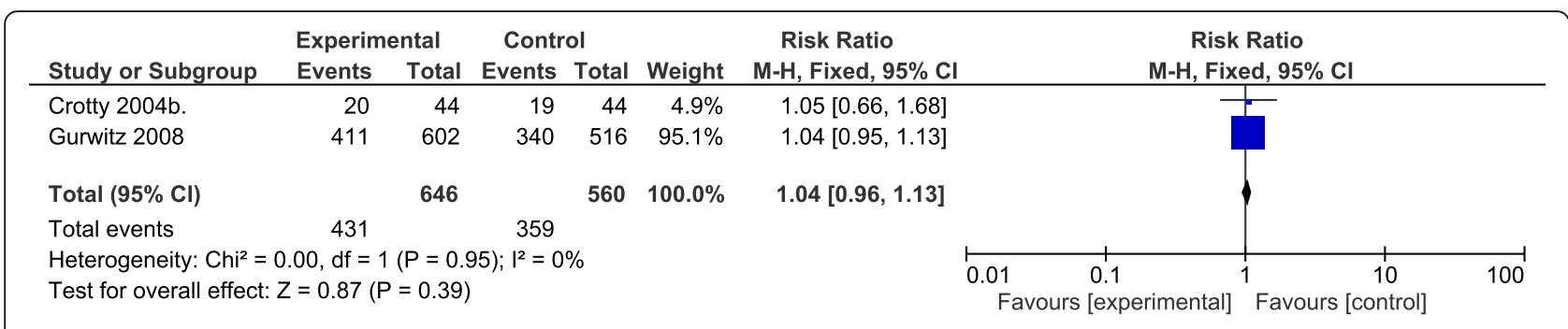

Fig. 11 A meta-analysis of the effect of interventions on adverse drug events (ADEs)

therefore, evaluating these interventions economically and their cost-effectiveness should be considered in future research.

\section{Strengths and limitations}

This systematic review was based on a comprehensive search of the literature that was limited to 25 studies with robust design (RCT, cRCT) and compared to previous reviews on related topics [12,44], our sample size may be regarded as sufficiently powered.

Another strength of this review was a focus only on residents in care homes. The nursing home population is at heightened risk of receiving multiple drugs because of their comorbidities. Therefore, evaluating specific available interventions optimising medications in this setting is required. We were able to complete metaanalyses to pooled the overall effects.

This study is not without limitations. We included only English language publications, which may lead to potential omission of other interventions. Although MEDLINE, PubMed, Google scholar, and PsycINFO databases were searched for relevant articles, some studies indexed in other databases may have been missed. We identified several additional articles manually which may indicate poor indexing of older studies and a lack of consistent terminology.

Due to the nature of the interventions, performance and detection biases may have resulted from the difficulty in maintaining blinding. Meta-analysis of some studies was difficult due to the variations in the measurement of specific outcomes. Certain outcomes, such as cognitive function, were examined in a limited number of articles, reducing the power of the analysis. Further, certain studies were small or had short study periods, which may potentially limit the effect of an intervention on the outcomes. We attempted to evaluate medication-related problems such as drug interactions, number of pharmacist recommendations etc. but these outcomes were not consistently reported in the studies and this our ability to draw any robust conclusions was limited.

Heterogeneity was notable among some studies included in the meta-analysis. The factors that caused this heterogeneity were difficult to discern. Due to differences in training, the characteristics of the nursing home residents, healthcare culture, the number of physicians' visits and their usual practices the ability to generalise findings from one country to another is difficult.

\section{Implications for research and practice}

In view of the considerable investment in strategies aimed at improving medication appropriateness in RACFs worldwide, our findings question the value of such interventions based on the apparent lack of outcomes that may be meaningful to RACF residents.

Large, high quality RCT studies are required to identify effective interventions to optimise medications used in RACFs. Regarding physicians or staff acceptance of the intervention, only limited information was provided in the studies. Further qualitative study

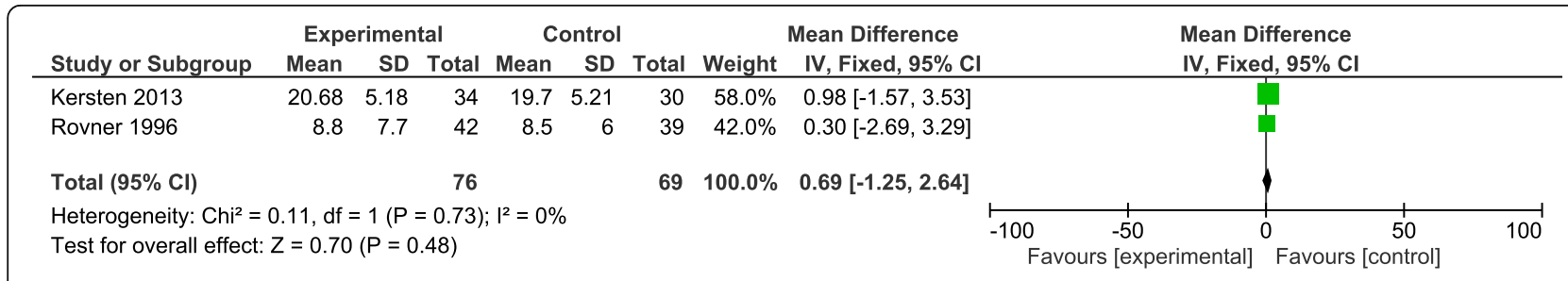

Fig. 12 A meta-analysis of the effect of interventions on cognitive function 
12. Loganathan $M$, Singh S, Franklin BD, Bottle A, Majeed A. Interventions to optimise prescribing in care homes: systematic review. Age Ageing. 2011; 40(2):150-62.

13. Moher D, Liberati A, Tetzlaff J, Altman DG. Preferred reporting items for systematic reviews and meta-analyses: the PRISMA statement. Ann Intern Med. 2009;151(4):264-9. https://doi.org/10.7326/0003-4819-151-4200908180-00135.

14. Avorn J, Soumerai SB, Everitt DE, Ross-Degnan D, Beers MH, Sherman D, et al. A randomized trial of a program to reduce the use of psychoactive drugs in nursing homes. N Engl J Med. 1992;327(3):168-73. https://doi.org/ 10.1056/NEJM199207163270306.

15. Rovner BW, Steele CD, Shmuely Y, Folstein MF. A randomized trial of dementia care in nursing homes. J Am Geriatr Soc. 1996;44(1):7-13. https:// doi.org/10.1111/j.1532-5415.1996.tb05631.x.

16. Meador KG, Taylor JA, Thapa PB, Fought RL, Ray WA. Predictors of antipsychotic withdrawal or dose reduction in a randomized controlled trial of provider education. J Am Geriatr Soc. 1997;45(2):207-10. https://doi.org/ 10.1111/j.1532-5415.1997.tb04509.x.

17. Schmidt IK, Claesson CB, Westerholm B, Nilsson LG. Physician and staff assessments of drug interventions and outcomes in Swedish nursing homes. Ann Pharmacother. 1998;32(1):27-32. https://doi.org/10.1111/j.15325415.1998.tb01017.x

18. Schmidt I, B. Claesson C, Westerholm B, Nilsson LG, Svarstad BL. The impact of regular multidisciplinary team interventions on psychotropic prescribing in Swedish nursing homes. J Am Geriatr Soc 1998;46(1):77-82. DOI: https:// doi.org/10.1177/106002809803200102.

19. Schmidt IK, Fastbom J. Quality of drug use in Swedish nursing homes. Clin Drug Investig. 2000;20(6):433-46. https://doi.org/10.2165/00044011200020060-00006.

20. Claesson CB, Schmidt IK. Drug use in Swedish nursing homes. Clin Drug Investig. 1998;16(6):441-52. https://doi.org/10.2165/00044011-19981606000004.

21. Furniss L, Burns A, Craig SK, Scobie S, Cooke J, Faragher B. Effects of a pharmacist's medication review in nursing homes. Randomised controlled trial. Br J Psychiatry. 2000;176:563-7. https://doi.org/10.1192/bjp.176.6.563.

22. Stein CM, Griffin MR, Taylor JA, Pichert JW, Brandt KD, Ray WA. Educational program for nursing home physicians and staff to reduce use of nonsteroidal anti-inflammatory drugs among nursing home residents: a randomized controlled trial. Med Care. 2001;39(5):436-45. https://doi.org/10. 1097/00005650-200105000-00004

23. Roberts MS, Stokes JA, King MA, Lynne TA, Purdie DM, Glasziou PP, et al. Outcomes of a randomized controlled trial of a clinical pharmacy intervention in 52 nursing homes. Br J Clin Pharmacol. 2001;51(3):257-65. https://doi.org/10.1046/j.1365-2125.2001.00347.x.

24. Crotty M, Halbert J, Rowett D, Giles L, Birks R, Williams H, et al. An outreach geriatric medication advisory service in residential aged care: a randomised controlled trial of case conferencing. Age Ageing. 2004;33(6):612-7. https:// doi.org/10.1093/ageing/afh213.

25. Crotty M, Rowett D, Spurling L, Giles LC, Phillips PA. Does the addition of a pharmacist transition coordinator improve evidence-based medication management and health outcomes in older adults moving from the hospital to a long-term care facility? Results of a randomized, controlled trial. Am J Geriatr Pharmacother. 2004;2(4):257-64. https://doi.org/10.1016/j. amjopharm.2005.01.001.

26. Crotty M, Whitehead C, Rowett D, Halbert J, Weller D, Finucane P, et al. An outreach intervention to implement evidence based practice in residential care: a randomized controlled trial. BMC Health Serv Res. 2004;4(1):6-2. https://doi.org/10.1186/1472-6963-4-6.

27. Fossey J, Ballard C, Juszczak E, James I, Alder N, Jacoby R, et al. Effect of enhanced psychosocial care on antipsychotic use in nursing home residents with severe dementia: cluster randomised trial. Bmj. 2006; 332(7544):756-61. https://doi.org/10.1136/bmj.38782.575868.7C.

28. Zermansky AG, Alldred DP, Petty DR, Raynor DK, Freemantle N, Eastaugh J, et al. Clinical medication review by a pharmacist of elderly people living in care homes--randomised controlled trial. Age Ageing. 2006;35(6):586-91. https://doi.org/10.1093/ageing/afl075.

29. Gurwitz JH, Field TS, Rochon P, Judge J, Harrold LR, Bell CM, et al. Effect of computerized provider order entry with clinical decision support on adverse drug events in the long-term care setting. J Am Geriatr Soc. 2008;56(12): 2225-33. https://doi.org/10.1111/j.1532-5415.2008.02004.x.
30. Field TS, Rochon P, Lee M, Gavendo L, Baril JL, Gurwitz JH. Computerized clinical decision support during medication ordering for long-term care residents with renal insufficiency. J Am Med Inform Assoc. 2009;16(4):480-5. https://doi.org/10.1197/jamia.M2981.

31. Patterson SM, Hughes CM, Crealey G, Cardwell C, Lapane KL. An evaluation of an adapted U.S. model of pharmaceutical care to improve psychoactive prescribing for nursing home residents in northern Ireland (fleetwood northern Ireland study). J Am Geriatr Soc. 2010;58(1):44-53. https://doi.org/ 10.1111/j.1532-5415.2009.02617.x

32. Testad I, Ballard C, Bronnick K, Aarsland D. The effect of staff training on agitation and use of restraint in nursing home residents with dementia: a single-blind, randomized controlled trial. J Clin Psychiatry. 2010;71(1):80-6. https://doi.org/10.4088/JCP.09m05486oli.

33. Lapane KL, Hughes CM, Daiello LA, Cameron KA, Feinberg J. Effect of a pharmacist-led multicomponent intervention focusing on the medication monitoring phase to prevent potential adverse drug events in nursing homes. J Am Geriatr Soc. 2011;59(7):1238-45. https://doi.org/10.1111/j.15325415.2011.03418.x

34. Pope G, Wall N, Peters CM, O'Connor M, Saunders J, O'Sullivan C, et al. Specialist medication review does not benefit short-term outcomes and net costs in continuing-care patients. Age Ageing. 2011;40(3):307-12. https:// doi.org/10.1093/ageing/afq095.

35. Kersten H, Molden E, Tolo IK, Skovlund E, Engedal K, Wyller TB. Cognitive effects of reducing anticholinergic drug burden in a frail elderly population: a randomized controlled trial. J Gerontol A Biol Sci Med Sci. 2013;68(3):2718. https://doi.org/10.1093/gerona/gls176.

36. Milos V, Rekman E, Bondesson A, Eriksson T, Jakobsson U, Westerlund T, et al. Improving the quality of pharmacotherapy in elderly primary care patients through medication reviews: a randomised controlled study. Drugs Aging. 2013;30(4):235-46. https://doi.org/10.1007/s40266-013-0057-0.

37. Frankenthal $D$, Lerman $Y$, Kalendaryev $E$, Lerman $Y$. Intervention with the screening tool of older persons potentially inappropriate prescriptions/ screening tool to alert doctors to right treatment criteria in elderly residents of a chronic geriatric facility: a randomized clinical trial. J Am Geriatr Soc. 2014;62(9):1658-65. https://doi.org/10.1111/jgs.12993.

38. García-Gollarte F, Baleriola-Júlvez J, Ferrero-López I, Cuenllas-Díaz Á, CruzJentoft AJ. An educational intervention on drug use in nursing homes improves health outcomes resource utilization and reduces inappropriate drug prescription. J Am Med Dir Assoc. 2014;15(12):885-91. https://doi.org/ 10.1016/j.jamda.2014.04.010.

39. Pitkala KH, Juola A-L, Kautiainen $H$, Soini $H$, Finne-Soveri UH, Bell JS, et al. Education to reduce potentially harmful medication use among residents of assisted living facilities: a randomized controlled trial. J Am Med Dir Assoc. 2014;15(12):892-8. https://doi.org/10.1016/j.jamda.2014.04.002.

40. Connolly MJ, Boyd M, Broad JB, Kerse N, Lumley T, Whitehead N, et al. The aged residential care healthcare utilization study (ARCHUS): a multidisciplinary, cluster randomized controlled trial designed to reduce acute avoidable hospitalizations from long-term care facilities. J Am Med Dir Assoc. 2015;16(1):49-55. https://doi.org/10.1016/j.jamda.2014.07.008.

41. Potter K, Flicker L, Page A, Etherton-Beer C. Deprescribing in frail older people: a randomised controlled trial. PLoS One. 2016;11(3):e0149984. https://doi.org/10.1371/journal.pone.0149984.

42. Higgins JP, Altman DG, Gøtzsche PC, Jüni P, Moher D, Oxman AD, et al. The Cochrane Collaboration's tool for assessing risk of bias in randomised trials. Bmj. 2011;34(3):5423-928. https://doi.org/10.1136/bmj.d5928.

43. Patterson SM, Cadogan CA, Kerse N, Cardwell CR, Bradley MC, Ryan C, et al. Interventions to improve the appropriate use of polypharmacy for older people. Cochrane Database Syst Rev. 2014(10). DOl:org/https://doi.org/10. 1002/14651858.CD008165.pub4.

44. Alldred DP, Kennedy MC, Hughes C, Chen TF, Miller P. Interventions to optimise prescribing for older people in care homes. Cochrane Database Syst Rev. 2016;2:CD009095. https://doi.org/10.1002/14651858.CD009095. pub3.

\section{Publisher's Note}

Springer Nature remains neutral with regard to jurisdictional claims in published maps and institutional affiliations. 